\title{
Creating inclusive campus communities: The vital role of peer mentorship in inclusive higher education
}

\author{
Catherine Lewis, DMA
}

\begin{abstract}
Across the country, colleges are opening their doors to students with intellectual and developmental disabilities. At University of Rochester (UR), we coordinate one such initiative called "Transition Opportunities at University of Rochester (TOUR).” Inclusive higher education at UR is based on the philosophy that ACCESS + SUPPORT = SUCCESS. In order to help our campus grow in intellectual diversity, we cannot simply open our doors to students with intellectual and developmental disabilities (IDD).We must also provide support to help students thrive academically and socially during their college education.
\end{abstract}

At the heart of TOUR are symbiotic mentoring relationships. When traditional undergraduates mentor fellow students with IDD, they gain academic and teaching skills, greater disability/diversity awareness, and an understanding of how and why inclusive communities are valuable. In turn, students with IDD find greater inclusion on their campus and invaluable academic and social skills that will launch them into self-determined lives as contributing citizens of their community.

This paper will focus especially on the growth of academic inclusion on our campus, strategies for training and supporting undergraduate academic coaches, and stories about the impact of these peer mentoring relationships on traditional UR students, their colleagues with disabilities, and our campus as a whole.

\section{Keywords}

Disability, inclusion, higher education, mentoring, accessibility

\section{Introduction: Who belongs in college?}

We live in an exciting time. Across the United States, scholars, activists, educators, families, and students are fueling progress around the accessibility of higher education. From programs that make college more affordable to initiatives that support low-income and first generation college students to pursue their postsecondary dreams, we are witnessing positive and impactful change in the higher education world today. But there are still some among us to whom the option of college is still rarely presented. Students with intellectual and developmental disabilities (IDD) have the lowest percentage of postsecondary enrollment of any category of people with disabilities (Newman, Wagner, Knokey, Marder, Nagle, Shaver, Schwarting, 2011). Only 23\% of high school students with IDD go on to attend a two- or four-year college. (Grigal, Hart, \& Migliore, 2011).

But change cannot happen if we simply open the college door to students with IDD. We must also 
address attitudes and expectations around who belongs on a college campus. Those of us working in inclusive higher education for people with IDD are often confronted with the question, "What's the point?”. Might we be “wasting our time” (Grigal \& Hart, 2010) offering college courses to students with these kinds of disabilities? As a person with a lifelong physical disability and a professional working in higher education for students with intellectual disabilities, the author of this paper will address this question by offering an alternate definition for the immense term 'disability.'

Disability is typically associated with deficit: a person with a disability is defined as someone "who has a physical or mental impairment that substantially limits one or more major life activities, a person who has a history or record of such an impairment, or a person who is perceived by others as having such an impairment (ADA, 1990).” The author openly acknowledges the challenges associated with disability. But disability is a rich life experience: something that has the potential to impact one's life in positive and challenging ways. As such, it must not simply be classified as deficit or limitation. The author chooses to define disability as "necessary creativity." For, no matter what type of disability a person experiences, navigating the world with an unconventional body, mind, or set of senses mandates that we become creative, flexible, and adaptable. Disability-however it manifests—necessitates a creative approach to life.

When considering access to college for people with IDD, we must first embrace the assets and strengths of people who are intellectually diverse, but it is imperative that we also provide a supportive and accommodating environment for learning. The formula for successful inclusion is access plus support. Peer mentorship plays a direct and significant role in making the college environment supportive and welcoming for people with IDD. Thanks to provisions in the Higher Education Opportunity Act (HEOA) of 2008, colleges are beginning to open their doors wider (Lee, 2009). The HEOA contains provisions to provide funding, model demonstration projects on campuses, and a national coordinating center for inclusive postsecondary education (Lee, 2009). As a result of this support, over 250 colleges internationally are currently supporting students with IDD (Think College, 2009). Many of these initiatives involve strong peer mentoring initiatives (Paiewonsky, Mecca, Daniels, Katz, Nash, Hanson, \& Gragoudas, 2010).

As we work to foster a more holistic, asset-centered understanding of disability on our campuses, it is helpful to take a card from sociocultural researchers Norma Gonzalez, Luis Moll, and Cathy Amanti. These scholars have researched and articulated a framework they call "funds of knowledge" (Gonzalez, Moll, \& Amanti, 2005). This concept begins with the presumption of competence; it shines a light on knowledgeable acquired because of, not in spite of, individuals' unique social, cultural, and familial experiences and histories (Gonzalez et al., 2005). Moll is heartened by the recent trend among scholars to "use the concept [of funds of knowledge] and [adapt] it to their own realities” (Moll, 2015). Viewing individual experiences of disability through a funds-of-knowledge lens can yield powerful, perspective-changing results. How do all the aspects of our life interconnect and make a person who they are? How does the experience of disability flavor one's academic and social behaviors, abilities, and strategies? What lessons — what strengths — might one's experience of disability impart? The concept of funds of knowledge is at the heart of TOUR mentor training and preparation. When recruiting academic coaches to support their peers with IDD, a primary consideration is avoidance of a charity mindset. Instead, we search for mentors open to learning with and from their mentee. If mentors begin by presuming competence, the pitfalls of a deficit mindset, including negative impact on mentees' sense of ability and possibility, may be avoided. 


\section{What does college look like for people with intellectual and developmental disabilities?}

Students with intellectual and developmental disabilities choose to attend college for many of the same reasons other students do. As anyone who has had the opportunity to attend college knows, higher education is not simply about taking courses on a college campus. People come to college for many reasons: to immerse themselves in a field of study, to follow their passions, to become socially connected, and to explore careers. Ideally, college culminates in readiness for the "real world." But to be truly prepared upon graduation involves possessing more than academic skills. Students must also have social networks to lean on, strategies for maintaining health and wellness, tools to be engaged members of their communities, knowledge of opportunities for continuing education, and skills to obtain and maintain employment. Inclusive college initiatives offer students with IDD explicit support and training in each of these areas.

Research has been done on the impact of college for students with intellectual and developmental disabilities in particular. Students with IDD who attend college...

- Increase their social networks and self-determination (Grigal \& Hart, 2010)

- Earn a 73\% higher income than those who do not go to college (Migliore, Butterworth, \& Hart, 2009)

- $\quad$ Are 26\% more likely to get a job (Migliore, Butterworth, \& Hart, 2009)

Such multi-faceted initiatives truly do take a village, as the saying goes. We've seen the exciting benefits of partnership at University of Rochester (UR) in our inclusive college initiative, Transition Opportunities at UR (TOUR).

\section{A history of Transition Opportunities at University of Rochester (TOUR)}

Since 2010 TOUR has been a partnership between: (a) Rochester Center for Community Leadership at University of Rochester; (b) the Institute for Innovative Transition at the Warner School of Education; (c) Monroe \#1 BOCES (an organization which provides special education services to students in several districts throughout Monroe County, NY); and (d) Lifetime Assistance, Inc., an adult agency that supports people with disabilities as they transition into adult life and pursue employment. Fewer campus and community partnerships were involved when TOUR began twentyfour years ago.

Transition Opportunities at University of Rochester was launched in 1997 when a Memorandum of Understanding (MOU) was established between University of Rochester and Monroe \#1 Board of Cooperative Educational Services (BOCES). This agreement opened the door for students with IDD to come to the University of Rochester campus and participate in a transition-to-adulthood program taught by special education professionals from BOCES. At this time in TOUR's history, the program had a dedicated, separate space on campus. Students with IDD received a rich education in independent living, health and wellness, and employment preparation. They had access to campus resources including the library, dining centers, and recreation facilities. But for twenty years, TOUR students were without access to the college courses University of Rochester offered to its traditional 
students. Their transition and independent living education was of excellent quality, but decidedly separate from the rest of the campus community.

A pivotal moment took place for TOUR in 2010, when University of Rochester became one of fortyfour campuses nationwide to receive funding from a Transition and Postsecondary Programs for Students with Intellectual Disabilities (TPSID) grant awarded by the Department of Education. TPSID grants are designed to either expand existing programs for students with IDD or develop brand new initiatives in colleges across the United States (Grigal \& Hart, 2010). Grant recipients are funded for five years and are charged with following the Think College Standards, Quality Indicators, and Benchmarks for Inclusive Higher Education (Think College, 2009) developed by Think College at University of Massachusetts-Boston, the national coordinating center for the TPSID grant project. These guidelines illuminate best practices for campuses with regard to the following areas: (a) inclusive academic access; (b) career development; (c) campus membership; (c) selfdetermination; (e) alignment with college systems and practices; (f) coordination and collaboration; (g) sustainability; and (h) ongoing evaluation (Think College, 2009). A significant growth spurt occurred over the course of the five-year TPSID grant, as we worked to align with best practices and grow as an inclusive campus community.

Traditional college students have become more actively involved with and connected to TOUR since the outset of the TPSID grant. In 2010, Rochester Center for Community Leadership (RCCL) developed a social mentoring program wherein traditional undergraduates were hired as paid mentors who facilitated participation in campus life. But after two years of this paid social mentorship model, undergraduates expressed interest in transitioning to an unpaid, student-led approach to increasing social inclusion for TOUR students. They helped TOUR critique "paid friendship" and suggested that students on campus had much to gain from supporting and getting to know TOUR students simply by being their friends. After several months of thoughtful planning, students at University of Rochester formed and launched a University-recognized student organization called "People First Initiative" (PFI). Their mission is as follows:

"People First Initiative is an awareness organization that is dedicated to creating and fostering inclusion of individuals with disabilities on a social front. Our mission is to create equal and reciprocal relationships between typically developing individuals and individuals with disabilities to reduce misconceptions based in prejudice. We believe that such relationships are mutually beneficial, and are the first step in creating an equitable society in which diversity of ability is celebrated” (About PFI, 2015).

PFI hosts a number of different regular events on campus, from a disability-related speaker series to campus accessibility tours led by students with disabilities. In addition to general disability awareness, PFI students interact regularly with TOUR students, going with them to concerts and sports events, cooking meals together, and hosting a twice-weekly TOUR Coffee Hour at the campus Starbucks, where all students on campus are encouraged to stop by and connect with students in TOUR. PFI has also collaborated with other disability-focused student initiatives on our campus, including UR chapters of national organizations like Special Olympics and Eye to Eye. From hosting a campus-wide campaign to end the use of the "R-word" to inviting their peers to a "Share Your Story Night” where undergraduates discuss their experiences of disability across their lifespan, students are raising the volume on conversations about disability and inclusion. Student leadership 
and collaboration is key in these awareness-raising, culture-changing efforts. Ryder and Mitchell (2013) studied the dynamics among peers in college and found that, "to discuss questions or concerns about their own ethical and moral thinking and the challenges they face, students turn to other students more often than they turn to faculty or student affairs personnel.”

\section{Academic mentorship}

In both Fall 2012 and Spring 2013, a TOUR student asked to participate in a college course, something TOUR students had never done, historically. Both semesters, RCCL obtained approval from College administration and professors, and two TOUR students sat in UR classes. While the opportunity was meaningful for the students, they expressed significant concern about not having enough support to feel comfortable or successful in classes. As a response, Rochester Center for Community Leadership piloted a new Academic Coaching program, wherein undergraduate students were hired and underwent significant training in academic mentoring strategies, executive functioning development, the history developmental disability, and other relevant topics. Coaches were paired 1:1 with a TOUR student whom they mentored and coached both in and outside the classroom for an entire semester. TPSID grant funding paid their wages. As illustrated in the TOUR College Course Access chart below, academic inclusion for TOUR students has increased exponentially since the initiation of a formal academic coaching program.

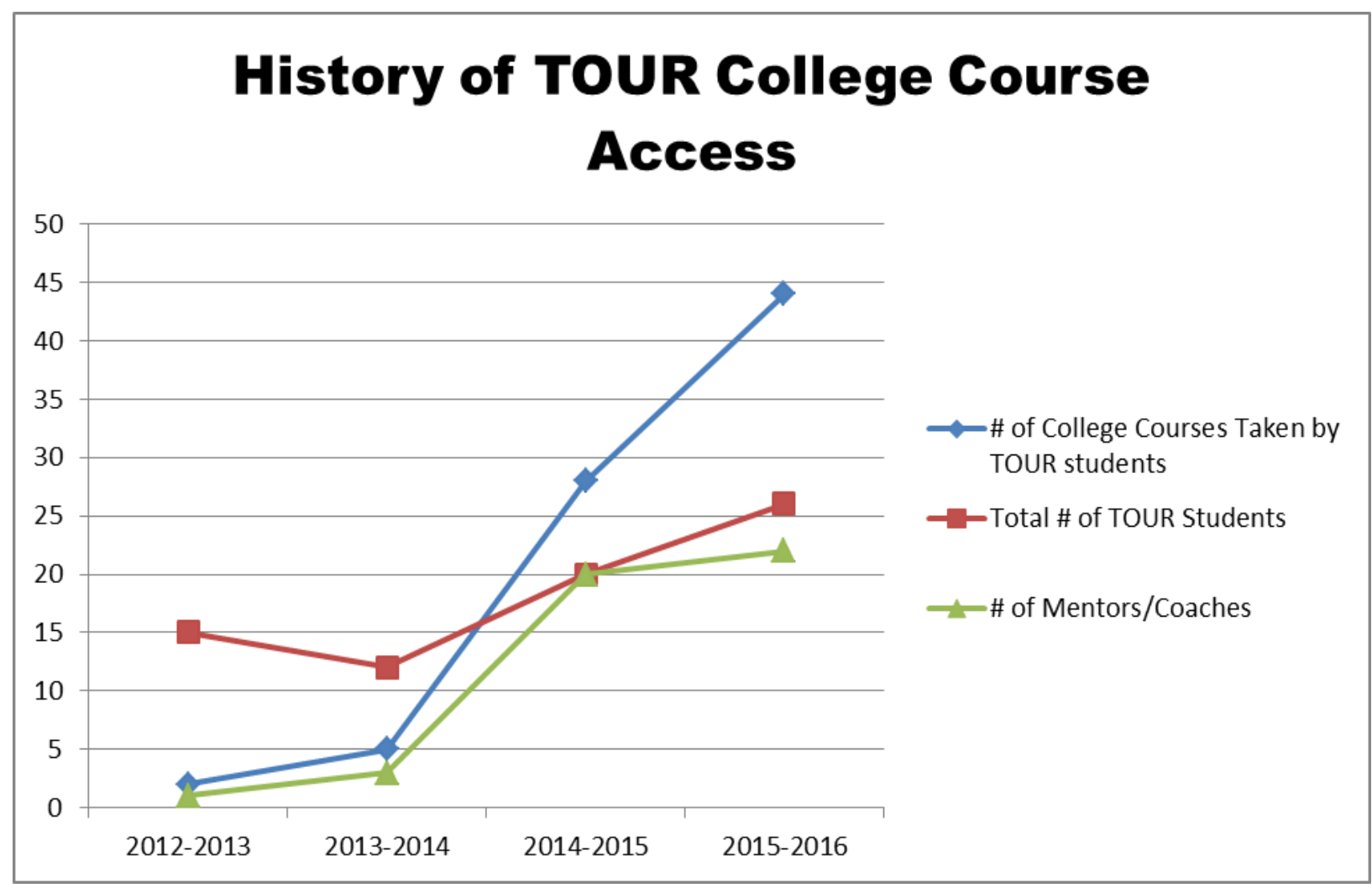

Figure 1. History of TOUR College Course Access. Image owned by the Author. 
Peer mentorship impacts both mentors and mentees in powerful ways. These benefits are captured in feedback received from both TOUR students and their academic coaches. TOUR students have shared these insights about working with peer mentors in their college classes:

- "The mentors are a really good thing. During my college class, they break it down into steps. It's really hard for me to take notes and keep up with my notes when the teacher is talking. But when I had my mentor, they took notes. So I only wrote down important things, and then compared notes with them. With their help I was better able to understand and succeed.” (2014, TOUR student interview)

- “These are college classes and they're hard. But you can use the mentors. You can’t keep interrupting the teachers during class when you don't understand. But working with a mentor helps with any questions you have. Every person is different. For me, anything academic is a struggle. But for someone else, it could be stressful meeting new people. You take it step by step. Everything is going to be okay. There's a lot of support around.” (2014, TOUR student interview)

When asked to articulate what others should know about inclusive higher education and the benefits of mentorship, academic coaches shared the following points:

- "People should know that being more inclusive makes higher education more open to new ideas, better possibilities, and different perspectives that help make us better people.” (2016, TOUR academic coach interview)

- “Inclusive higher education doesn’t just benefit people with disabilities, or even just the people directly involved, it benefits the whole community.” (2016, TOUR academic coach interview)

- "Mentoring is about a constant change in perspective on how you see yourself and society... Mentoring is learning.” (2016, TOUR academic coach interview)

- "People try not to look at our differences, and I feel like that is the greatest mistake any one individual can make... With our differences come unique perspectives and individuality.” (2016, TOUR academic coach interview)

\section{The ongoing development of TOUR}

During the 2014-2015 year the TOUR team focused heavily on planning for the conclusion of the TPSID grant, which occurred in October 2015. Recognizing the vital nature of the academic coaching program that had thus far been grant-funded, the University of Rochester approved a budget for RCCL's continued facilitation of TOUR academic coaching, including wages for student academic coaches and a new experiential learning course that is now mandatory for all coaches. The course is called "Creating inclusive campus communities: disability, mentorship, and inclusive higher education” and covers topic areas including: (a) disability history; (b) disability legislation and policy; (c)universal design for learning; (d) establishing appropriate boundaries in mentoring relationships; and (e) strategies for supporting executive-functioning skill development. During the course, students are encouraged to engage in regular reflection and actively connect their mentoring 
work with TOUR with the theoretical concepts and discussions they encounter in class. Special consideration is given to authentically highlighting the voices of citizens and scholars with disabilities, both via guest presentations and assigned readings/viewings.

Another key step forward for TOUR has been the development of a TOUR student portfolio that codifies the specific requirements for completion of the program. All students enrolled in TOUR now have consistent requirements regarding college academics, campus social experiences, paid and unpaid internships, and independent living/transition education. This portfolio was first implemented during the 2015-2016 academic year, and required that every TOUR student take at least one college course per academic year. In accordance with this requirement, all TOUR students enrolled in at least one college course of their choice during the 2015-2016 academic year, and we expect a similar result at the conclusion of the 2016-2017 year. Notably, about two-thirds of TOUR students have requested go above the minimum requirement and take one course each semester over the past two years. Each TOUR student taking a college course is required to be paired with a trained and supervised academic coach.

As part of their job, coaches must attend class alongside their mentee and meet for individual coaching sessions for at least one hour per week. Since the implementation of the academic coaching program, we have had only a handful of faculty decline a request to place a TOUR student in their course. It is important to note that faculty have most often declined for capacity reasons (no spaces left in a yoga course or studio art class, for example). By and large, UR faculty have been extraordinarily receptive to including TOUR students in their courses. The support of an alwayspresent academic coach has proven vital in helping professors effectively navigate significant adaptions, accommodations, and behavior/engagement expectations in their classrooms. In addition to the logistical and practical benefits for faculty, the reciprocal benefits of mentoring in TOUR are best captured by highlights (see Table 1 and Table 2) from the feedback academic coaches provided at the conclusion of the Fall 2015 semester $(n=12)$.

Table 1.

Effects on understanding accessibility, inclusion, and experiences of students with disabilities

- $100 \%$ of academic coaches surveyed agree or strongly agree that being a peer mentor has impacted their perspective on issues related to students' with disabilities access to higher education.

- $100 \%$ of academic coaches surveyed agree that being a peer mentor made them more sensitive to how higher education can support students with disabilities, intellectual and otherwise.

- $100 \%$ of academic coaches surveyed strongly agree that being a peer mentor made them more aware of discrimination that occurs for students with disabilities, on campus and off. 
Table 2.

Effects on understanding of self and career options

- $\quad 75 \%$ of academic coaches surveyed agree or strongly agree that being in class with their mentee has impacted the way they think about how they learn best.

- $\quad 77.8 \%$ of academic coaches surveyed agree or strongly agree that being a peer mentor made them rethink their future career interests.

- Students surveyed indicated that they discussed their experience as a mentor to a student with an intellectual disability...

o in their own classes (55.5\%)

o casually with friends (100\%)

o to recommend the experience to friends and peers (100\%)

- $100 \%$ of academic coaches surveyed rated their experience coaching a student with an intellectual disability as "very positive."

\section{Conclusion}

As the TOUR program has evolved and grown, our campus community has seen firsthand the powerful, symbiotic nature of mentorship. When traditional undergraduates mentor their peers with IDD, they gain academic and teaching skills, greater disability and diversity awareness, and an understanding of how and why inclusive communities are valuable. In turn, students with IDD find greater inclusion on their campus and invaluable academic and social skills that will launch them into self-determined lives as contributing citizens of their community. In addition to the notable impact on individual students, we are witnessing a culture shift throughout our campus community.

Recently, UR's Writing and Speaking Fellows program reached out to request a training for their tutors about TOUR and effective mentorship strategies when working with students with disabilities. As we dove into an overview of inclusive higher education on our campus, one student raised her hand. "I think there's a TOUR student in my dance class right now," she shared. "I didn't realize he had an intellectual disability or that he was part of TOUR. I just noticed that he had a mentor in class and didn't think much about it. We're choreographing a dance right now and he's in my small group. I just wanted to share that his ideas have been so creative... Having him in our class hasn't had any negative impact. It's just a benefit. He's made us more thoughtful, creative dancers.” Here we find evidence of a funds of knowledge approach to disability. This student has not perceived her peer in terms of his impairment. Instead, she has noticed his positive impact on the class dynamic and the ideas generated during group activities. Anecdotes like this are powerful evidence of a shift away from a deficit model of disability toward embracing the disability difference as a valuable component of human diversity. 


\section{References}

About People First Initiative. (2015). Retrieved from

https://ccc.rochester.edu/organization/peoplefirstiniative/about

Americans with Disabilities Act of 1990, Pub. L. No. 101-336, §2, 104 Stat. 328 (1991).

González, N., Moll, L., \& Amanti, C. (Eds). (2005). Funds of knowledge: Theorizing practices in households, communities and classrooms. Mahwah, NJ: Erlbaum.

Grigal M., Hart, D., Migliore, A. (2011) Comparing the transition planning, postsecondary education, and employment outcomes of students with intellectual and other disabilities. Career Development for Exceptional Individuals, 34(1), 4-17. https://doi.org/10.1177/0885728811399091

Grigal, M., \& Hart, D. (2010). Think College! Postsecondary Education Options for Students with Intellectual Disabilities. Baltimore: Paul H. Brookes.

Lee, Stephanie (2009). Overview of the Federal Higher Education Opportunity Act. Think College. Boston, MA: University of Massachusetts Boston, Institute for Community Inclusion.

Migliore, A., Butterworth, J., \& Hart, D. (2009). Postsecondary Education and Employment Outcomes for Youth with Intellectual Disabilities. Think College Fast Facts, 1(1).

Moll, L. (2015). Funds of Knowledge. Retrieved from https://www.youtube.com/watch?v=aWS0YBpGkkE

Newman, L., Wagner, M., Knokey, A. M., Marder, C., Nagle, K., Shaver, D., \& Schwarting, M. (2011). The post-high school outcomes of young adults with disabilities up to 8 years after high school. A report from the national longitudinal transition study-2 (NLTS2). Menlo Park, CA: SRI International. Retrieved from www.nlts2.org/reports

Paiewonsky, M., Mecca, K., Daniels, T., Katz, C., Nash, J., Hanson, T., \& Gragoudas, S. (2010). Students and Educational Coaches: Developing a Support Plan for College. Think College Insight Briefs, 1(4).

Ryder, A. J., Mitchell, J. J. (2013). Measuring Campus Climate for Personal and Social Responsibility. New Directions for Higher Education, 2013 (164), 31-48. https://doi.org/10.1002/he.20074

Think College. (n.d.). Home - Think College: College Options for People with Intellectual Disabilities. Retrieved from http://www.thinkcollege.net/

Think College. (2010). Standards for Inclusive Higher Education - Think College: College Options for People with Intellectual Disabilities. Retrieved from http://www.thinkcollege.net/topics/standards-survey 


\section{Author information}

Catherine Lewis serves as Associate Director, School and Community Relations, in the Office of Admissions at University of Rochester. She previously held the position of Assistant Director, Rochester Center for Community Leadership at University of Rochester, where she taught about disability, mentorship, and inclusive higher education, coordinated academic access and peer mentor supports for students with intellectual and developmental disabilities, oversaw a literacy tutoring program in partnership with Rochester City School District, and advised undergraduate student organizations dedicated to political and community engagement. Dr. Lewis received both her Master of Music and Doctor of Music degrees from the Eastman School of Music, and studied Higher Education at University of Rochester's Warner School of Education.

Dr. Catherine Lewis, DMA

Assistant Director, Rochester Center for Community Leadership

University of Rochester

107C Lattimore Hall

Rochester, NY

Email: catherine.lewis@rochester.edu

Telephone: 585-275-8172 